\title{
Changes in thermic limits and acclimation assessment of an alpine plant by chlorophyll fluorescence analysis: $F_{v} / F_{m} v s$. Rfd
}

\author{
A.V. PERERA-CASTRO, P. BRITO and A.M. GONZÁLEZ-RODRÍGUEZ
}

Department of Botany, Ecology and Plant Physiology, Universidad de La Laguna (ULL), 38200 La Laguna, Tenerife, Spain.

\begin{abstract}
A comparison between maximum quantum yield of PSII photochemistry $\left(\mathrm{F}_{\mathrm{v}} / \mathrm{F}_{\mathrm{m}}\right)$ and chlorophyll (Chl) fluorescence decrease ratio $\left(\mathrm{R}_{\mathrm{fd}}\right)$ in low and high temperatures resistance is assessed in a seasonal study of the acclimation of Pterocephalus lasiospermus. Analyzing the regression adjustment of both parameters and the lethal temperatures $\left(\mathrm{LT}_{50}\right)$, $\mathrm{R}_{\mathrm{fd}}$ resulted to be a more sensitive indicator parameter for low and high temperature treatments, since thermic resistance estimated with $\mathrm{R}_{\mathrm{fd}}$ parameter was never higher than those estimated with $F_{v} / F_{m}$. Furthermore, the use of $F_{v} / F_{m}$ led to an overestimation of the acclimation phenomena, with $6 \mathrm{C}^{\mathrm{o}}$ of maxima difference between both parameters. Using $\mathrm{R}_{\mathrm{fd}}$ as indicator parameter, P. lasiospermus acclimated to low temperatures but it kept on being a sensitive species (the lowest $\mathrm{LT}_{50}$ values only achieved $-9.9 \pm 0.3^{\circ} \mathrm{C}$ ). However, any heat acclimation was observed $\left(\mathrm{LT}_{50}\right.$ around $43.5^{\circ} \mathrm{C}$ ). Thus, according to $\mathrm{R}_{\mathrm{fd}}$ evaluation of thermic threshold, this species could be in risk of damage for low temperatures in this alpine ecosystem.
\end{abstract}

Additional key words: freezing acclimation, heat, high mountain, Pterocephalus lasiospermus, temperature resistance, Teide National Park, vitality index.

*e-mail: aglerod@ull.es

Abbreviations: a.s.1 - above sea level; Chl - chlorophyll; $\mathrm{F}_{0}$ - minimal fluorescence yield of the dark-adapted state; $\mathrm{F}_{0}{ }^{\prime}-$ minimal fluorescence yield of the light-adapted state; $F_{m}-$ maximal fluorescence yield of the dark-adapted state; $F_{m}{ }^{\prime}-m_{a x i m a l}$ fluorescence yield of the light-adapted state; $F_{s}$ - steady-state fluorescence yield; $F_{v}$ - variable fluorescence; $F_{v} / F_{m}-$ maximal quantum yield of PSII photochemistry; $\mathrm{LT}_{50}$ - temperatures which cause a $50 \%$ of damage; $\mathrm{R}_{\mathrm{fd}}-$ Chl fluorescence decrease ratio or vitality index.

\section{Acknowledgements}

We thank referees for comments that substantially improved this paper. Thanks to Roberto Dorta, for statistical support. Thanks to Project CGL2010-21366-C04-04 (MCI, Spanish Government) and to ACIISI (Canary Government) for a grant to P.B., all cofinanced by FEDER. Thanks to Teide National Park direction for support and installation facilities.

\section{Introduction}

Chl $a$ fluorescence has been widely recognized as a noninvasive technic for monitoring photosynthetic activity and for assessing plant responses to a variety of environmental stresses (Baker 2008). Low and high temperatures have been shown to be two of those stressful factors (Neuner and Pramsohler 2006, Ehlert and Hincha 2008), since both membrane fluidity and protein conformation changes are affected (Ruelland and Zachowski 2010).

Several methods have been developed to assess extreme temperature tolerance. Generally, the calculation of LT $_{50}$ values, the lethal temperature at which irreversible damage is provoked, is of interest, since it delimits resistance to thermic stress and allows comparisons between species. Probably, the most common methods used for the calculation of $\mathrm{LT}_{50}$ values are visual damage, electrolyte leakage and $\mathrm{Chl}$ fluorescence. However, in some species necrotic damage is not clearly observed (e.g. Sierra-Almeida and Cavieres 2010) or perceptible electrolyte release is not detected (e.g. Cieraad et al. 2012). Thus, the choice of the suitable Chl fluorescence parameter as indicator of thermic damage is of great importance. $F_{v} / F_{m}$ is one of the most known Chl fluorescence parameter and it reflects the state of the initial part of photosynthesis, it is, PSII and primary acceptor transport. Other several Chl parameters have been also described. One of them is the Chl fluorescence decrease ratio or the vitality index $\left(\mathrm{R}_{\mathrm{fd}}\right)$, introduced in the 1980s (Lichtenthaler et al. 1986, Haitz and Lichtenthaler 1988, Lichtenthaler and Rinderle 1988). $\mathrm{R}_{\mathrm{fd}}$ is a physiological straight-forward indicator of photosynthetic quantum conversion of leaves, it is, the capacity of using the potential photochemical activity of PSII under continuous irradiation, which is not really registered with $F_{v} / F_{m}$ (Haitz and Lichtenthaler 1988, Lichtenthaler et al. 2005a). $\mathrm{R}_{\mathrm{fd}}$ depends on the ongoing of the whole electron transport chain and final synthesis of ATP and NADPH, and has been demonstrated to be highly correlated with $\mathrm{CO}_{2}$ fixation (Haitz and Lichtenthaler 1988, Flexas et al. 2002, Lichtenthaler et al. 2005a). Thus, theoretically both parameters must show a different response to a thermic stress if different 
photosynthesis processes are involved. However, the thermic damage studies by chlorophyll fluorescence focus mainly in $\mathrm{F}_{\mathrm{v}} / \mathrm{F}_{\mathrm{m}}$ as indicator of damage (eg. Fisker et al. 1995, Germino and Smith 2000, Bannister and Lord 2006, Ehlert and Hincha 2008, Martínez-Peñalver et al. 2011, Sierra-Almeida and Cavieres 2012, Venn et al. 2013, Briceño et al. 2014, Pescador et al. 2016), and few studies consider $\mathrm{R}_{\mathrm{fd}}$ (Balota and Lichtenthaler 1999, Murkowski 2001, Mishra et al. 2014). Although contrasting between Chl fluorescence and electrolyte leakeage (Ehlert and Hincha 2008) and visual damage methods (Bannister et al. 2005) have been conducted, to our knowledge, studies that evidence simultaneously the variability in $L_{50}$ values obtained by $F_{v} / F_{m}$ and $R_{f d}$ are absent.

Many studies have been developed in order to determine low and high temperature resistance of many tropical, temperate and polar species (e.g. Sakai and Larcher 1987, Larcher 2003b). As a result, it has been reported that some species, including many plants from temperate climates, are able to increase their thermic resistance as a result of a previous exposition in a process termed acclimation, both to low temperatures (Thomashow 1999, Xin and Browse 2000, Pflug and Brüggerman 2012) and high temperatures (Dat et al. 1998, Larkindale and Huang 2004, Sheng et al. 2006, Wahid et al. 2007). Furthermore, most plants follow a variable annual cycle of acclimation and deacclimation (Larcher 2003c) and even in terms of heat-tolerance diurnal variations of $\mathrm{LT}_{50}$ values have also been reported (Buchner and Neuner 2003).

Temperature thresholds and acclimation phenomena are of special interest, since thermic stress is one of the most important limiting factors that determinate the plant survival, especially in alpine ecosystems, where freezing stress is the first environmental "filter" that a species has to pass to become "alpine" and where heat stress may appears every time solar radiation peaks and top soils dry (Körner 2003, Bannister et al. 2005, Larcher et al. 2010, Sierra-Almeida and Cavieres 2012). It is precisely in alpine ecosystems where climate change effects act more quickly than in other terrestrial habitats, causing biodiversity loss, habitat degradation and landscape modifications (Chersich et al. 2015), depending on the rate of climatic change, the species pool and the biogeographical region (Beniston 2003, Pauli et al. 2012). Among these high mountain habitats, the Mediterranean alpine ecosystems deserve particular attention for hosting a high number of endemic and rare plants (Pauli et al. 2003). In these privilege areas little detailed studies have been done (Cabrera 2002, Evangelista et al. 2016), including Mediterranean alpine ecosystem of Canary Islands (Spain), which is inside a hotspot of biodiversity in Macaronesia region (Myers et al. 2000). The most representative alpine ecosystem of the archipelago is harbored in Tenerife and preserved in Teide National Park, where a total of 168 alpine species with a $32 \%$ of endemics have been listed (Acebes et al. 2010).

Teide National Park has a typically cold winter with minimum air temperatures of -5 to $-2^{\circ} \mathrm{C}$ and maximum temperatures of 4 to $8^{\circ} \mathrm{C}$ (measured $1.5 \mathrm{~m}$ above ground level). Although during summer maximum temperatures can reach to $30^{\circ} \mathrm{C}$, annual mean temperatures maintain around $8^{\circ} \mathrm{C}$, which reflects a strong diurnal and seasonal oscillation in temperature, with $14.8^{\circ} \mathrm{C}$ of difference between the minimum and maximum temperature mean of the coldest and warmest month of the year (Del-Arco et al. 2006). The high radiation (500-1,000 $\mathrm{W} \mathrm{m}^{-2}$, the highest of Spain according to Meteorology State Agency, AEMET) and the very hard edaphic conditions with Leptosols as predominant soils (Rodríguez et al. 2014) are also characteristic factors of this singular ecosystem.

In this ecosystem, climate change studies have denoted an increase of $0.31 \pm 0.12^{\circ} \mathrm{C}$ each decade in the mean temperature since 1970 (Martín et al. 2012). Since 1944, the minimum and maximum mean temperatures have increased $1.18 \pm 0.4^{\circ} \mathrm{C}$ and 0.66 $\pm 0.52^{\circ} \mathrm{C}$, respectively, and taking into account that extreme temperatures are considered one of the most important limiting factor in this ecosystem, its vegetal structure could change radically, involving therefore a loss of biodiversity (Del-Arco et al. 2008).

Currently, one of the most abundant species in Teide National Park is the endemic alpine shrub Pterocephalus lasiospermus Link ex Buch whose distribution area is restricted to the highest part of Tenerife from 2,000 to 2,500 m a.s.1. In the 1960s this species had practically disappeared, but during the recent decades it has overexpanded at the expense of other nearby species (Martín and Wildpret, 1999). Therefore, this species is of special interest due to its emblematic character as well as the fact that cause factors for its abundance and distribution changes remind undefined and are of priority for Teide National Park managers.

Given the above, the present study has the aim of 1) evaluating sensitivity of both $F_{v} / F_{m}$ and $R_{f d}$ parameters in low and high temperature stress detection, and 2) determining the thermic limits and the annual tolerance of the endemic alpine evergreen shrub $P$. lasiospermus by chlorophyll fluorescence in order to contribute elucidating the reasons of its recently expansion.

\section{Materials and methods}

Study site and meteorological conditions: The study site was located at 2,070 $\mathrm{m}$ a.s.1. in the northeast exposed slope of Teide National Park (Tenerife, Canary Islands, Spain), close to El Portillo (28 $8^{\circ} 18^{\prime} 16.25^{\prime \prime} \mathrm{N}, 16^{\circ} 34^{\prime} 0.01^{\prime \prime} \mathrm{W}$ ). An automatic weather station (MiniCube VV/VX16, EMS, Brno, CZ) was installed and connected to a data logger programmed to record 30 min averages of environmental measurements taken every minute from $12^{\text {th }}$ December, 2013 to $24^{\text {th }}$ July, 2014. Air temperature (EMS33, EMS, Brno, CZ) was monitored in order to record all freezing events and to know the temperature context of each essay. Four essays were made during the end of 2013 and 2014: E1 (17 $7^{\text {th }}$ December), E2 (14 ${ }^{\text {th }}$ February), E3 (25 $5^{\text {th }}$ February) and E4 (24 $4^{\text {th }}$ July). Winter assays were developed according with the unpredictable freezing events which took place in the study site. The last assay was made in warm and dry period for comparisons of contrasted seasons. 
Plant material and sampling: The sampling of each essay was done early in the morning (around 7:00 and 9:00 a.m.), since the light exposure have been reported to increase $\mathrm{LT}_{50}$ values at heat temperatures (Buchner et al., 2013). The apical parts of the stems of $P$. lasiospermus were randomly collected from plants growing naturally in the study site. Each plume was chosen from the upper part of the shrub so as to avoid variation due to different microclimates. After collecting, plumes were immediately introduced in plastic bags with hydrated atmosphere in order to prevent samples from drying out and transported to the laboratory in boxes that maintain ambient temperature, avoiding extra heating of the samples. All samples were stored overnight until the beginning of the measurements and treatments the next day morning. Then, single, healthy leaves were selected homogeneously always belonging to $3^{\text {th }}-5^{\text {th }}$ node and carefully removed from the plume immediately before temperature treatments.

Temperature treatments: In each temperature essay, leaves were put into plastic hermetic bags with hydrated atmosphere. Both cooling and heating treatments were carried out in a circulated water bath (Hetofrig CB11E, Heto, Birkerød, Denmark). Samples were immediately exposed to the target temperature for an exposure time of $30 \mathrm{~min}$ (Larcher 2003b, González-Rodríguez et al. 2005). We are aware that the exposure of leaves to freezing temperatures without a slow decrease in temperature could affect their freezing resistance, however this procedure have been reported by others authors (Sierra-Almeida and Cavieres 2012). A thermocouple fixed to the leaves indicated the exact temperature of the leaves during the temperature treatment in order to avoid the thermoprotective effect of the bag. In the case of low temperature treatments, extracellular ice formation was confirmed by the observation of freezing exotherm. A total of 24 temperatures were selected (from -20 to 0 and 30 to $50^{\circ} \mathrm{C}$ in $2 \mathrm{~K}$ steps, and 20 and $25^{\circ} \mathrm{C}$ as non-damaging temperatures), except in E3 where only low temperatures were evaluated. Each temperature had a set of 59 leaves.

Chl $\boldsymbol{a}$ fluorescence measurements: Ch fluorescence parameters, $\mathrm{F}_{\mathrm{v}} / \mathrm{F}_{\mathrm{m}}$ and $\mathrm{R}_{\mathrm{fd}}$, were obtained with IMAGING-PAM fluorometer (Mini blue version, Walz GmbH, Effeltrich, Germany). Each fluorescence data was obtained by typical integration of all the pixels values of the whole leaf area, avoiding errors derivate from heterogeneity of the damage patterns (Lichtenthaler et al. 2005b). $\mathrm{F}_{\mathrm{v}} / \mathrm{F}_{\mathrm{m}}$ was calculated by applying a saturating light pulse ( $\mu$ mol (photon) $\mathrm{m}^{-2} \mathrm{~s}^{-1}>3,000$ ) both before (control) and after temperature treatment on each same leaf, with a delay of $1 / 2-1 \mathrm{~h}$ and after $24 \mathrm{~h}$. The thermal baths were done in a dark room, so that additional $30 \mathrm{~min}$ for dark adaptation after thermal bath was not needed. Once obtained $\mathrm{F}_{\mathrm{v}} / \mathrm{F}_{\mathrm{m}}$ after temperature treatment, a saturating and continuous actinic light (blue light $470 \mathrm{~nm}, 923 \mu \mathrm{mol}$ (photon) $\mathrm{m}^{-2} \mathrm{~s}^{-1}$, previously tested according to the $\mathrm{F}_{\mathrm{m}}$ ' and $F^{\prime}$ values matching) was switched on and the decrease of the fluorescence was recorded until achieving to steady state $\left(\mathrm{F}_{\mathrm{s}}\right) 5$ min later (Lichtenthaler et al. 2005a), allowing $\mathrm{R}_{\mathrm{fd}}$ calculation. Control $\mathrm{R}_{\mathrm{fd}}$ values were calculated for non-bath-subjected leaves $(n=5$ 9). All Chl fluorescence measurements were done at room temperature. In E1, measurement of Fs was not possible due to technical mishap.

Data and statistical analysis: Linear or non-linear regression between $F_{v} / F_{m}$ and $R_{f d}$ values was done fitting the data to a line or a curve by the Solver function of Microsoft Excel. The method employed to fit the regression curves was the least squares estimation (Seber and Wild 2003, De Lobo et al. 2013). The resulted model was tested with IBM SPSS Statistics 21 (IBM, EE.UU.).

$F_{v} / F_{m}$ and $R_{f d}$ values reach to zero in this species in dead leaves, so the percentage of leaf damage was equivalent to 1) the percentage of reduction of $\mathrm{F}_{\mathrm{v}} / \mathrm{F}_{\mathrm{m}}$ after treatment with respect to the measurements before treatment of the same leaf (control), and 2) the percentage of reduction of $R_{\mathrm{fd}}$ after treatment with respect to non-bath-subjected control leaves. It is considered that a 50\% of damage corresponds with lethal or irreversible damage, so that the temperatures which cause this percentage of damage are termed $\mathrm{LT}_{50}$ (Larcher 2003b). For calculation of $\mathrm{LT}_{50}$, percent damage was plotted against the treatment temperatures, so that the temperature at which a $50 \%$ of damage is produced could be calculated by linear regression fitted to the central (linear) part of the sigmoid relationship between the damaging temperature and the percentage of damage, using at least three temperatures (Bannister et al., 2005; Bannister, 2007). The regression models were obtained with StatGraphics (Centurion XVI.I, Manugistics, Rockville, USA) once tested normality and homoscedastic hypothesis. Apart from the mean value of $\mathrm{LT}_{50}$, the upper and lower limits of the intervals were estimated with a confident interval of $95 \%(\alpha=0.05)$ and the intercepts and slopes of the regression models were compared by F-test.

\section{Results}

Meteorological essays conditions: Air temperatures and freezing events recorded during the studied period are shown in Fig. 1. The first freezing event occurred on $12^{\text {th }}$ of December. It was short and the absolute minimum temperatures hardly dropped at $0.7^{\circ} \mathrm{C}$, with daily means of $2.1^{\circ} \mathrm{C}$. E1 was developed behind this first freezing event. Along January the temperatures dropped below zero several times, reaching to $-1.8^{\circ} \mathrm{C}$. From $15^{\text {th }}$ to $17^{\text {th }}$ of February, temperatures below zero were kept. It was the strongest freezing event of the year with absolute minimum of $-3.1^{\circ} \mathrm{C}$ and maximum of $0.8^{\circ} \mathrm{C}$. E2 and E3 were developed before and after this event, respectively, with a difference of 11 days. The last freezing event occurred on $25^{\text {th }}$ of May, when absolute minimum achieved $-1.3^{\circ} \mathrm{C}$. Finally, the last essay $-\mathrm{E} 4-$ was developed in a summer context where temperatures had gradually increased with absolute maximum around $28^{\circ} \mathrm{C}$ and absolute minimum around $10^{\circ} \mathrm{C}$. 
$\mathbf{F}_{\mathbf{v}} / \mathbf{F}_{\mathbf{m}}$ vs. $\mathbf{R}_{\mathbf{f d}}$ : All shown data are referred to the measurements taken after thermic treatment with a delay of $1 / 2-1 \mathrm{~h}$. The measurement developed after $24 \mathrm{~h}$ of thermic treatment are not shown, since there was neither additional damage nor recuperation values after this time.

Different behaviors were observed between both parameters depending on the period of the year and the temperatures, except in E1 where a comparison of $F_{v} / F_{m}$ and $R_{f d}$ values was not possible due to technical setback in the $R_{f d}$ measurements. At high temperatures, the correlation between $\mathrm{F}_{\mathrm{v}} / \mathrm{F}_{\mathrm{m}}$ and $\mathrm{R}_{\mathrm{fd}}$ was linear (Fig. 2A). On the contrary, at low temperatures, the data were fitted to a curve with an asymptote at the highest $\mathrm{F}_{\mathrm{v}} / \mathrm{F}_{\mathrm{m}}$ values (Fig. $2 B$ ), only perturbed by data of E4 (Fig. 2B, open circles), which showed a similar behavior to high temperatures. Thus, at low temperatures during winter $F_{v} / F_{m}$ values below 0.6 corresponded to $R_{\mathrm{fd}}$ values below 1, meanwhile when the damage was due to high temperatures $F_{\mathrm{v}} / \mathrm{F}_{\mathrm{m}}$ values of 0.6 equated to $R_{\mathrm{fd}}$ values around 3 .

This dissimilar sensitivity of both parameters was coherent with the found differences in the evaluation of the percentage of thermic damage obtained for each parameter (Fig. 3). In E2 and E3, the regression model fitted to low damage temperatures data resulted to have a significantly different intercept and slope from $\mathrm{F}_{\mathrm{v}} / \mathrm{F}_{\mathrm{m}}$ to $\mathrm{R}_{\mathrm{fd}}$ as indicator parameters (Fig. 3B,D compared with $C, E$ ). It means that in February essays (E2 and E3) low temperature treatments evaluated with $\mathrm{F}_{\mathrm{v}} / \mathrm{F}_{\mathrm{m}}$ provoked damage earlier and more slowly ( 0.43 and 0.63 times more slowly in E2 and E3, respectively) than when they were evaluated with $\mathrm{R}_{\mathrm{fd}}\left(\right.$ the rise in $1^{\circ} \mathrm{C}$ corresponded with 3.25 and $10.27 \%$ of damage more with $\mathrm{R}_{\mathrm{fd}}$ than with $\mathrm{F}_{\mathrm{v}} / \mathrm{F}_{\mathrm{m}}$ in $\mathrm{E} 2$ and E3, respectively). This differences was not significant at low temperatures treatments developed in $\mathrm{E} 4$ (Fig. $3 F, G$ ).

On the contrary, at high temperature treatment, the slope of the regression models did not significantly change between $\mathrm{F}_{\mathrm{v}} / \mathrm{F}_{\mathrm{m}}$ and $\mathrm{R}_{\mathrm{fd}}$ in both $\mathrm{E} 2$ and $\mathrm{E} 4$ (Fig. 3B,F compared with $C, G$ ). Only in E4 the intercept of the regression model was different depending on the parameter used, which not compromise the linear relation between both parameters at high temperatures already described (Fig. 2A).

LT $_{50}$ values and acclimation phenomena. The differences detected in intercepts and slopes of the correlation models of both $\mathrm{F}_{\mathrm{v}} / \mathrm{F}_{\mathrm{m}}$ and $\mathrm{R}_{\mathrm{fd}}$ above mentioned were reflected in calculation of $\mathrm{LT}_{50}$ values.

At high temperatures (Fig. $4 A$ ), $\mathrm{LT}_{50}$ values obtained with $\mathrm{F}_{\mathrm{v}} / \mathrm{F}_{\mathrm{m}}$ showed an increase of $1.9 \pm 1.6^{\circ} \mathrm{C}$ in $\mathrm{E} 4$ compared with $\mathrm{E} 1$ and $1.55 \pm 1.05^{\circ} \mathrm{C}$ compared with $\mathrm{E} 2$. On the contrary, $\mathrm{LT}_{50}$ values obtained with $\mathrm{R}_{\mathrm{fd}}$ did not show significant variation between $\mathrm{E} 2$ and E4. It is clear that from the winter to the summer (from E2 to E4) $F_{v} / F_{m}$ parameter registered an apparent acclimation to high temperatures that $\mathrm{R}_{\mathrm{fd}}$ did not show.

At low temperatures (Fig. $4 B$ ), $\mathrm{LT}_{50}$ values obtained with $\mathrm{F}_{\mathrm{v}} / \mathrm{F}_{\mathrm{m}}$ showed a decrease of $3.5 \pm 1.5^{\circ} \mathrm{C}$ between $\mathrm{E} 2$ to $\mathrm{E} 3$, which involved an acclimation phenomenon developed in 11 days. In $\mathrm{E} 4$ a loss of acclimation was observed in a range of $7 \pm 1^{\circ} \mathrm{C}$ from $\mathrm{E} 3$, reaching $\mathrm{LT}_{50}$ values of $4.25 \pm 1.25^{\circ} \mathrm{C}$ higher than in $\mathrm{E} 1 . \mathrm{LT}_{50}$ values obtained with $\mathrm{R}_{\mathrm{fd}}$ showed similar pattern but not so accentuated. In this case, the acclimation observed was $1.38 \pm 1.12^{\circ} \mathrm{C}$ in $\mathrm{E} 3$ respect to $\mathrm{E} 2$, meanwhile $\mathrm{LT}_{50}$ of $\mathrm{E} 3$ and $\mathrm{E} 4 \mathrm{did}$ not differ, not showing the deacclimation observed with $\mathrm{F}_{\mathrm{v}} / \mathrm{F}_{\mathrm{m}}$ values.

Regarding the differences between $\mathrm{LT}_{50}$ values obtained with both parameters, variable tendencies were observed depending on temperature treatments. So, at high temperatures, the divergences of both indicators were only significant in E4 with differences of $1.8 \pm 0.9^{\circ} \mathrm{C}$. At low temperatures $\mathrm{LT}_{50}$ values from $\mathrm{R}_{\mathrm{fd}}$ were significantly higher than $\mathrm{F}_{\mathrm{v}} / \mathrm{F}_{\mathrm{m}}$, except in July, when both indicators became equal. The highest difference between $\mathrm{LT}_{50}$ values from both parameters was found in E3 with values close to $6^{\circ} \mathrm{C}$.

\section{Discussion}

$F_{v} / F_{m}$ and $R_{f d}$ showed different response at low and high temperature damage assessment. At high temperatures damage, linear regression between both parameters is explained by the equal sensitivity that both PSII and thylakoid lamellae likely experiment. Consistently with our data, temperature threshold of PSII has been reported to be one degree under net photosynthesis limit at high temperatures (Enami et al. 1994, Larcher 2003a). Other studies using the determination of the critical temperature $\left(\mathrm{T}_{\mathrm{c}}\right)$ by Chl fluorescence reported that $\mathrm{T}_{\mathrm{c}}$ of PSII and $\mathrm{LT}_{50}$ assessed by visual damage had a good linear correlation (Bilger et al., 1984), suggesting once again that PSII photochemistry may be the most heat sensitive process of photosynthesis. On the other hand, photochemical reactions in thylakoid lamellae and carbon metabolism in the stroma of chloroplast have been also suggested as the primary sites of injury at high temperatures (Wahid et al. 2007).

On the contrary, it is recognized that thylakoid membranes are the primary site of freezing damage in plant cells, thus affecting photosynthesis and $\mathrm{CO}_{2}$ fixation (Hincha et al. 1996, Devacht et al. 2011). Low temperatures always tend to inhibit electron transport via increased membrane viscosity through alterations in the biophysical properties of thylakoid lipids. This is more strongly affected than processes involved in energy transfer and its photochemical transformation (Huner et al. 1998, Hendrickson et al. 2006). That is the reason why $\mathrm{R}_{\mathrm{fd}}$ was more sensitive for estimating photosynthesis damage and could register damage faster than $F_{v} / F_{m}$ at low temperatures. The cause of the loss of the asymptotic relation between both parameters at low temperature in summer remains unknown. We speculate that the differences of high radiation between summer and winter could be involved. It has been reported that the inhibitory effects of low temperature treatment can be greater after a period of illumination (Sassenrath et al. 1990, Flexas et al. 1999, Allen et al. 2000). According to our meteorological station data, irradiation increased a 66\% 
between summer and winter. Although chronic photoinhibition in both non-treated $F_{v} / F_{m}$ and $R_{f d}$ controls did not show any seasonal variation (data not shown), PSII could be more prone to inhibition and it could equate the limiting character of PSII and electron transport at low temperatures treatment on summer. Anyway, $\mathrm{R}_{\mathrm{fd}}$ kept on being the more sensitive parameter in all essays, since the thermic resistance estimated with $R_{\mathrm{fd}}$ parameter was never higher than those estimated with $\mathrm{F}_{\mathrm{v}} / \mathrm{F}_{\mathrm{m}}$.

Visual damage evaluation has been considered as the method to obtain the reference $\mathrm{LT}_{50}$ values (Buchner et al. 2013). So, in that study an underestimation of heat tolerance assessed by $F_{v} / F_{m}$ comparing with visual damage method has been reported. Unfortunately, this could not be assessed in our species because of an unclear colour difference between necrotic and healthy tissues mainly due to a high density of hair. At low temperatures, Neuner and Buchner (1999) found that indices of damage derived from $\mathrm{F}_{\mathrm{v}} / \mathrm{F}_{\mathrm{m}}$ overestimated winter frost resistance compared with estimation of $\mathrm{LT}_{50}$ by digital image analysis, indicating a higher sensitivity of visual damage method. Answering if $\mathrm{LT}_{50}$ values obtained by $\mathrm{R}_{\mathrm{fd}}$ would show a different sensitivity compared with visual damage method is outstanding.

In addition to $\mathrm{R}_{\mathrm{fd}}$ values, a complete analysis of the slow phase of chlorophyll fluorescence transients (OPSMT) can be potentially used as indicators of freezing stress in photosynthetic apparatus (Mishra et al., 2015). Apart from thermic stress, it has been previously reported that $R_{f d}$ is more sensitive to a variety of stress factors than $F_{v} / F_{m}$. Regarding water stress, Schreiber and Bilger (1985) showed that even at a very low relative water content of $36 \%$, where electron transport is severely inhibited, variable fluorescence is almost unchanged, suggesting that the PSII donor side and the primary reaction were not affected. Horgan and Zabkiewicz (2008) showed how $R_{\mathrm{fd}}$ was more sensitive and better indicator than $\mathrm{F}_{\mathrm{v}} / \mathrm{F}_{\mathrm{m}}$ for herbicides tolerance assessment.

This different sensitivity of both parameters is also important in order to describe a real acclimation phenomenon. In this study, a maximum difference of $6^{\circ} \mathrm{C}$ between $\mathrm{LT}_{50}$ values calculated with both parameters was reported in winter. Furthermore, $\mathrm{LT}_{50}$ values obtained with $\mathrm{F}_{\mathrm{v}} / \mathrm{F}_{\mathrm{m}}$ parameter had a higher variation along the studied period than ones obtained with $\mathrm{R}_{\mathrm{fd}}$. In winter, a freezing acclimation was observed with both parameters but it was more remarked with $F_{v} / F_{m}$ than with $R_{f d}$. In summer $F_{v} / F_{m}$ parameter registered an apparent acclimation to high temperatures that $R_{\mathrm{fd}}$ did not show. Moreover, with $\mathrm{F}_{\mathrm{v}} / \mathrm{F}_{\mathrm{m}}$ it was showed that the freezing acclimation obtained in E3 was lost in summer, meanwhile with $\mathrm{R}_{\mathrm{fd}}$ it was kept. It could mean that - at least in $P$. lasiospermus- processes involved in the efficiency of PSII and reduction of first acceptors $\mathrm{Q}_{\mathrm{A}}$ give a more flexible response to seasonal variations and freezing events, although they are not the main limiting factor of photosynthesis at extreme temperatures. Although $\mathrm{R}_{\mathrm{fd}}$ parameter was more sensitive and better indicator of thermic damage and acclimation phenomena, it does not have a unique healthy range defined in contrast to $\mathrm{F}_{\mathrm{v}} / \mathrm{F}_{\mathrm{m}}$ parameter, whose interval have been determined in $0.74-0.85$ (Lichtenthaler et al. 2005a). Even, it has been reported that, depending on light exposition, healthy $\mathrm{R}_{\mathrm{fd}}$ values can strongly vary in the same species, with an interval of 1.3-2.7 for shade leaves, or 3.0-5.5 in sun exposed leaves (Lichtenthaler et al. 2005b). In our case, $P$. lasiospermus is an alpine plant daily exposed to high irradiation, so it does not surprise that $\mathrm{R}_{\mathrm{fd}}$ values achieved 5.5 in the controls and a $\mathrm{R}_{\mathrm{fd}}$ value of 2.75 is considered a $50 \%$ of damage. Thus, every time $\mathrm{R}_{\mathrm{fd}}-\mathrm{LT}_{50}$ values are requested for unknown species and light conditions, a control $\mathrm{R}_{\mathrm{fd}}$ value must be well defined.

According to all abovementioned, the thermic limits and acclimation phenomena of $P$. lasiospermus were evaluated by the most sensitive parameter, $R_{\mathrm{fd}}$. Depending on the species, it may take a few days to several weeks to reach maximum levels of freezing tolerance (Xin and Browse 2000). In P. lasiospermus, acclimation took place after exposition to strong freezing events in a short period of time between E2 and E3 (11 days), what is expected for a plant subjected to low temperatures every night due to strong diurnal and seasonal oscillation (Del-Arco et al. 2006). Although many researchers showed that heat acclimation might be acquired by a non-lethal heat treatment (Dat et al. 1998, Larkindale and Huang 2004, Sheng et al. 2006, Wahid et al. 2007), no heat acclimation was registered in this species in summer according to $\mathrm{LT}_{50}$ calculated with $\mathrm{R}_{\mathrm{fd}}$.

Furthermore, even under acclimation, this species is quite sensitive to freezing temperatures compared to other high mountain species (Larcher 2003b, Taschler and Neuner, 2004), since, according to $\mathrm{R}_{\mathrm{fd}}$ values, P. lasiospermus suffered an irreversible damage at $-9.9 \pm 0.3^{\circ} \mathrm{C}$. This threshold is quite close to the absolute minimum air temperatures registered in Teide National Park $\left(-9.8^{\circ} \mathrm{C}\right)$. As minimal leaf temperatures have been reported to be even lower than air temperature in alpine plants (Braun et al. 2002), freezing events could be an important risk factor in this species.

Regarding high temperatures, the threshold at $43.5^{\circ} \mathrm{C}$ must be carefully considered since strong diurnal variations of $\mathrm{LT}_{50}$ have been reported and underestimation of $\mathrm{LT}_{50}$ could be determined in ex situ essays (Buchner et al. 2013, Buchner and Neuner 2003). On the other hand, although air temperature registered in Teide National Park achieves to $30.4^{\circ} \mathrm{C}$, leaf temperature is probably significantly higher during daytime, depending on the exposure to irradiation, the wind and the morphological growth habit of the species (Braun et al. 2002). Recording of leaf temperatures under high air temperatures is of great interest.

Seventy years ago, P. lasiospermus was described as an uncommon endemic species (Sventenius 1946), nevertheless, nowadays is one of the main species of Teide National Park landscape. Even though some authors have pointed out a selective herbivory as one possible explanation of the expansion of P. lasiospermus (Martín and Wildpret 1999), the current spread of this species seem to be also in coherence with our data, since the mean temperatures of Teide National Park have increased $1.3^{\circ} \mathrm{C}$ in the last 90 years and the freezing events have been less frequent (Martín et al. 2012). However, we cannot confirm with certainty that climate warming is the primary driver of current population changes in P. lasiospermus, since photosynthesis is not the only physiological process limited by low temperatures. Additional studies are demanded in order to make reliable predictions about how the increasing temperatures will affect the distribution of this species, as well as making the best biodiversity conservation management performance in this unique ecosystem. 


\section{Concluding Remarks}

In this study, $R_{\mathrm{fd}}$ has been demonstrated as a more sensitive parameter for thermic damage assessment. The evaluation of $F_{v} / F_{m}$ as the unique indicator of thermic damage could lead to an erroneous estimation of both temperature tolerance and acclimation at low and high temperatures. Thus, we propose the use of $R_{f d}$ instead of $F_{v} / F_{m}$ as indicator of thermic damage, determining for each species and light conditions the healthy $\mathrm{R}_{\mathrm{fd}}$ values.

According to $\mathrm{R}_{\mathrm{fd}}$ as indicator of thermic damage, low temperature acclimation was not enough to stop considering $P$. lasiospermus as a sensitive species compared with other alpine plants, since the lowest $\mathrm{LT}_{50}$ values achieved $-9.9 \pm 0.3^{\circ} \mathrm{C}$. On the contrary, any heat acclimation was observed, with $\mathrm{LT}_{50}$ values around $43.5^{\circ} \mathrm{C}$ during the studied period. Thus, according to $\mathrm{R}_{\mathrm{fd}}$ evaluation of thermic threshold, this species could be in risk of damage for low temperatures in this ecosystem.

\section{References}

Acebes J.R., León M.C., Rodríguez M.L. et al.: Pteridophyta, Spermatophyta. - In: Arechavaleta M., Rodríguez S., Zurita N., García A. (ed.): Lista de especies silvestres de Canarias. Hongos, plantas y animales terrestres. Gobierno de Canarias. Santa Cruz de Tenerife 2010 [Spanish].

Allen D.J., Ratner K., Giller Y.E. et al:: An overnight chill induces a delayed inhibition of photosynthesis at midday in mango (Mangifera indica L.). - J. Exp. Bot. 51: 1893-1902, 2000.

Baker N.R.: Chlorophyll Fluorescence: A Probe of Photosynthesis In Vivo. - Annu. Rev. Plant Biol. 59: 89-113, 2008.

Bannister P.: A touch of frost? Cold hardiness of plants in the Southern Hemisphere. - New Zealand Journal of Botany 45: 1-33, 2007.

Bannister P., Lord J.M.: Comparative winter frost resistance of plant species from southern Africa, Australia, New Zealand, and South America grown in a common environment (Dunedin, New Zealand). - New Zealand Journal of Botany 44(2): 109-119, 2006.

Bannister P., Maegli T., Dickinson K.J.M. et al:: Will loss of snow cover during climatic warming expose New Zealand alpine plants to increased frost damage? - Oecologia 144: 245-256, 2005.

Balota M., Lichtenthaler H.K.: Red Chlorophyll Fluorescence as an Ecophysiological method to assess the Behaviour of Wheat Genotypes under drought and heat. - Cereal Res. Commun. 22: 179-187, 1999.

Beniston M.: Climatic change in mountain regions: a review of possible impacts. Climatic Change 59: 5-31, 2003.

Bilger H.W., Schreiber U., Lange O.L.: Determination of leaf heat resistance: comparative investigation of chlorophyll fluorescence changes and tissue necrosis methods. - Oecologia 63: 256-262, 1984.

Braun V., Buchner O., Neuner G.: Thermotolerance of photosystem 2 of three alpine plant species under field conditions. Photosynthetica 40(4): 587-595, 2002.

Briceño V.F., Harris-Pascal D., Nicotra A.B. et al.: Variation in snow cover drives differences in frost resistance in seedlings of the alpine herb Aciphylla glacialis. - Environ. Exp. Bot. 106: 174-181, 2014.

Buchner O., Karadar M., Bauer I., Neuner G.: A novel system for in situ determination of heat tolerance of plants: first results on alpine dwarf shrubs. - Plant Methods 9:7, 2013.

Buchner O.,Neuner G.: Variability of Heat Tolerance in Alpine Plant Species Measured at Different Altitudes - Arctic, Antarctic, and Alpine Research 35(4): 411-420, 2003.

Cabrera M.: Ecophysiological responses of plants in ecosystems with Mediterranean-like climate and high mountain environments. - Rev. Chil. Hist. Nat. 75: 625-637, 2002 [Spanish].

Chersich S., Rejšek K., Vranová V., Bordoni M., Meisina C.: Climate change impacts on the Alpine ecosystem: an overview with focus on the soil- a review. Journal of Forest Science 61: 496-514, 2015.

Cieraad E., McGlone M., Barbour M.M., Huntley B.: Seasonal Frost Tolerance of Trees in the New Zealand Treeline Ecotone. Arct. Antarct. Alp. Res. 44(3): 332-342, 2012.

Dat J., Lopez-Delgado H., Foyer C.H., Scott I.M.: Parallel changes in $\mathrm{H}_{2} \mathrm{O}_{2}$ and catalase during thermotolerance induced by salicylic acid or heat acclimation in mustard seedling. - Plant. Physiol., 116: 1351-1357, 1998.

De Lobo A.F., De Barros M.P., Dalmagro H.J. et al.: Fitting net photosynthetic light-response curves with Microsoft Excel - a critical look at the models. - Photosynthetica 51: 445-456, 2013.

Del-Arco M., Pérez-de-Paz P.L., Acebes J.R. et al.: Bioclimatology and climatophilous vegetation of Tenerife (Canary Islands). Ann. Bot. Fennici 43: 167-192, 2006.

Del-Arco M.: Consecuencias del cambio climático sobre la flora y vegetación canaria. - In: Méndez J.M., Vázquez M. (ed.). El Cambio Climático en Canarias. - Academia Canaria de Ciencias. Serie Monografías Pp: 79-100. ISBN: 978-84-612-2434-0, 2008 [Spanish].

Devacht S., Lootens P., Baert J. et al.: Evaluation of cold stress of young industrial chicory (Cichorium intybus L.) plants by chlorophyll $a$ fluorescence imaging. I. Light induction curve. - Photosynthetica 49: 161-171, 2011. 
Ehlert, B., Hincha D.K.: Chlorophyll fluorescence imaging accurately quantifies freezing damage and cold acclimation responses in Arabidopsis leaves. - Plant Methods 4: 12-19, 2008.

Enami I., Kitamura M., Tomo T., Isokawa Y., Ohta H., Katoh S.: Is the primary cause of thermal inactivation of oxygen evolution in spinach PS II membranes release of the extrinsic $33 \mathrm{kDa}$ protein or of Mn? - Biochim. Biophys. Acta 1186: 52-58, 1994.

Evangelista A., Frate L., Carranza M.L., Attorre F., Pelino G., Stanisci A.: Changes in composition, ecology and structure of highmountain vegetation: a re-visitation study over 42 years. - AoB Plants 8: plw004; doi:10.1093/aobpla/plw004, 2016.

Fisker S.E., Rose R., Haase D.L.: Chlorophyll fluorescence as a measure of cold hardiness and freezing stress in $1+1$ douglas-Fir seedlings. - Forest Science 41(3): 564-575, 1995.

Flexas J., Badger M., Chow W.S. et al.: Analysis of the relative increase in photosynthesic $\mathrm{O}_{2}$ uptake when photosynthesis in grapevine leaves is inhibited following low night temperatures and/or water stress. - Plant Physiol. 121: 675-684, 1999.

Flexas J., Escalona J.M., Evain S. et al:: Steady-state chlorophyll fluorescence $\left(\mathrm{F}_{\mathrm{s}}\right)$ measurements as a tool to follow variations of net $\mathrm{CO}_{2}$ assimilation and stomatal conductance during water-stress in C3 plants. - Physiol. Plantarum 114: 231-240, 2002.

Germino M.J., Smith W.K.: High resistance to low-temperature photoinhibition in two alpine, snowbank species. - Physiol. Plantarum 110:98-95, 2000.

González-Rodríguez Á.M., Jiménez M.S., Morales D.: Seasonal and intraspecific variation of frost tolerance in leaves of three Canarian laurest forest tree species. - Ann. For. Sci. 62: 423-428, 2005.

Haitz M., Lichtenthaler H.K.: The measurement of $\mathrm{R}_{\mathrm{fd}}$-values as plant vitality indices with the portable field fluorometer and the PAM-fluorometer. - In: Lichtenthaler, H.K. (ed.): Applications of Chlorophyll Fluorescence. Pp. 249-254. Kluwer Academic Publishers, Dordrecht - Boston - London 1988.

Hendrickson L., Vlčková A., Selstam E. et al.: Cold acclimation of the Arabidopsis dgd1 mutant results in recovery from photosystem I-limited photosynthesis. - FEBS letters 580: 4959-4968, 2006.

Hincha D.K., Sieg F., Bakaltcheva I., Köth H., Schmitt J.M.: Freeze-thaw damage to thylakoid membranes: specific protection by sugars and proteins. - In: Steponkus P.L. (ed.): Low-temperature Biology. Pp: 141-183. JAI PRESS LTD, London, 1996.

Horgan D.B., Zabkiewicz J.A.: Fluorescence decline ratio: comparison with quantum yield ratio for plant physiological status and herbicide treatment responses. - NZ Plant Protection 61:169-173, 2008.

Huner N.P.A., Öquist G., Sarhan F.: Energy balance and acclimation to light and cold. - Trends Plant Sci. 3: 224-230, 1998.

Körner, C.: Climatic stress. - In: Körner C. (ed.): Alpine Plant Life. Functional Plant Ecology of High Mountain Ecosystems Pp. 101-114. Springer, Berlin Heidelberg New York 2003.

Larcher W. (ed.): Functional Disturbances and Injury Patterns. - In: Physiological Plant Ecology. Ecophysiology and Stress Physiology of Functional Groups. Pp. 374-375. Springer, Berlin 2003 a.

Larcher W. (ed.): Stress Due to Extreme Temperatures. - In: Physiological Plant Ecology. Ecophysiology and Stress Physiology of Functional Groups. Pp. 364-367. Springer, Berlin 2003b.

Larcher W. (ed.): Survival Capacity Under Heat stress. - In: Physiological Plant Ecology. Ecophysiology and Stress Physiology of Functional Groups. Pp. 375-380. Springer, Berlin 2003c.

Larcher W., Kainmüller C., Wagner J.: Survival types of high mountain plants under extreme temperatures. - Flora 205: 3-18, 2010.

Larkindale J., Huang B.: Changes of lipid composition and saturation level in leaves and roots for heat-stressed and heatacclimated creeping bentgrass (Agrostis stolonifera). - Environ. Exp. Bot. 51: 57-67, 2004.

Lichtenthaler H.K., Buschmann C., Knapp N.: How to correctly determine the different chlorophyll fluorescence parameters and the chlorophyll fluorescence decrease ratio $\mathrm{R}_{\mathrm{fd}}$ of leaves with the PAM fluorometer. - Photosynthetica 43: 379-393, 2005a.

Lichtenthaler H.K., Buschmann C., Rinderle U., Schmuck G.: Application of chlorophyll fluorescence in ecophysiology. -Radiat. Environ. - Biophys. 25: 297-308, 1986.

Lichtenthaler H.K., Langsdorf G., Lenk S., Buschmann C.: Chlorophyll fluorescence imaging of photosynthetic activity with the flash-lamp fluorescence imaging system. - Photosynthetica 43: 355-369, 2005b.

Lichtenthaler H.K., Rinderle U.: The role of chlorophyll fluorescence in the detection of stress conditions in plants. - CRC crit. Rev. Anal. Chem. 19: 29-85, 1988.

Martín J.L., Bethencourt J., Cuevas-Agulló E.: Assessment of global warming on the island of Tenerife, Canary Islands (Spain). Trends in minimum, maximum and mean temperatures since 1944. - Climatic Change 114: 343-355, 2012.

Martín V.E., Wildpret W.: Evolución de la flora y vegetación en las Cañadas del Teide en los últimos cincuenta años (1946-1996). In: Fernández A. (ed.) - Estudios Canarios. Anuario del Instituto de Estudios Canarios en La Universidad de La Laguna Pp. 930. La Laguna, 1999.

Martínez-Peñalver A., Reigosa M.J., Sánchez-Moreiras A.M.: Imaging chlorophyll $a$ fluorescence reveals specific spatial distributions under different stress conditions. - Flora 206: 836-844, 2011.

Mishra A., Hájek J., Tuháčková T., Barták M., Mishra K.B.: Features of chlorophyll fluorescence transients can be used to investigate low temperature induced effects on photosystem II of algal lichens from polar regions. - Czech polar reports 5: 99111, 2015.

Mishra A., Heyet A.G., Mishra K.B.: Chlorophyll fluorescence emission can screen cold tolerance of cold acclimated Arabidopsis thaliana accessions. - Plant Methods 10:38, 2014. 
Murkowski A.: Heat stress and spermidine: effect on chlorophyll fluorescence in tomato plants. - Biol. Plantarum 44(1): 53-57, 2001.

Myers N., Mittermeier R.A., Mittermeier C.G., da Fonseca G.A.B., Kent J.: Biodiversity hotspots for conservation priorities. Nature 403: 853-858, 2000.

Neuner G., Buchner O.: Assessment of foliar frost damage comparison of in vivo fluorescence with other viability tests. - J. Appl. Bot. 73: 50-54, 1999.

Neuner G., Pramsohler M.: Freezing and high temperature thresholds of photosystem 2 compared to ice nucleation, frost and heat damage in evergreen subalpine plants. - Physiol. Plantarum 126: 196-204, 2006.

Pauli H., Gottfried M., Dirnböck T., Dullinger S., Grabherr G.: Assessing the long-term dynamics of endemic plants at summit habitats. - In: Nagy L., Grabherr G., Körner C., Thompson D.B.A., (ed.): Alpine biodiversity in Europe. Pp. $195-207$. Springer, Berlin 2003.

Pauli H., Gottfried M., Dullinger S. et al.: Recent plant diversity changes on Europe's mountain summits. Science 336: 353-355, 2012.

Pescador D.S., Sierra-Almeida Á., Torres P.J., Escudero A.: Summer Freezing Resistance: A Critical Filter for Plant Community Assemblies in Mediterranean High Mountains. - Front. Plant Sci.: doi: 10.3389/fpls.2016.00194, 2016.

Pflug E., Brüggermann W.: Frost-acclimation of photosynthesis in overwintering Mediterranean holm oak, grown in Central Europe. - International Journal of Plant Biology: doi: http://dx.doi.org/10.4081/pb.2012.e1, 2012.

Rodríguez N., Notario J., Arbelo C.D., Rodríguez-Rodríguez A., Guerra J.A.: Spatial variability of soil properties and soils classification in Teide National Park (Tenerife, Canary Islands). - In: Arrouays D., McKenzie N., Hempel J., Richer A., McBratney A. (ed.): GlobalSoilMap. Basis of the global spatial soil information system Pp. 191-196. London 2014.

Ruelland E., Zachowski A.: How plants sense temperature. - Environ. Exp. Bot. 69(3): 225-232, 2010.

Sakai A., Larcher W.: Frost Resistance in Plants. - In: Billings W.D., Galley E., Lange O.L, Olson S., Remmert H. (ed.): Ecological Studies Vol. 62. Frost Survival of Plants. Responses and Adaptation to Freezing Stress Pp. 138-153. SpringerVerlag, Berlin 1987.

Sassenrath G.F., Donald R.O., Portis A.R.: Impaired reductive activation of stromal bisphosphatases in tomato leaves following low-temperature exposure at high light. - Arch. Biochem. and Biophys. 282(2): 302-308, 1990.

Schreiber U., Bilger W.: Rapid Assessment of stress effects on plant leaves by chlorophyll fluorescence measurements. Presented at Nato Advanced Research Workshop, Sesimbra, Portugal 1985.

Seber G.A.F., Wild C.J.: Nonlinear Regression. - Wiley-Interscience, Hoboken 2003.

Sheng X., Jianlong L., Xinquan Z., Hong W., Langjun C.: Effects of heat acclimation pretreatment on changes of membrane lipid peroxidation, antioxidant metabolites, and ultrastructure of chloroplast in two cool-season turfgrass species under heat stress. Environ. Exp. Bot. 56: 274-285, 2006.

Sierra-Almeida A., Cavieres L.: Summer freezing resistance of high-elevation plant species changes with ontogeny. - Environ. Exp. Bot. 80: 10-15, 2012.

Sierra-Almeida A., Cavieres L., Bravo L.A.: Freezing resistance varies within the growing season and with elevation in high Andean species of central Chile. - New Phytol. 182: 461-469, 2009.

Sierra-Almeida A., Cavieres L.A.: Summer freezing resistance decreased in high-elevation plants exposed to experimental warming in the central Chilean Andes. - Oecologia 163(1): 267-276, 2010a.

Sierra-Almeida A., Cavieres L., Bravo L.A: Freezing resistance of high-elevation plant species is not related to their height or growth-form in the Central Chilean Andes. - Environ. Exp. Bot. 69: 273-278, 2010b.

Sventenius E.S.: Notas sobre la Flora de las Cañadas de Tenerife. Ministerio de Agricultura, Madrid 1946 [Spanish].

Taschler D., Neuner G.: Summer frost resistance and freezing patterns measured in situ in leaves of major alpine plant growth forms in relation to their upper distribution boundary. - Plant Cell Physiol. 27: 737-746, 2004.

Thomashow M.F.: Plant cold acclimation: Freezing tolerance genes and regulatory mechanisms. - Annu. Rev. Plant Physiol. Plant Mol. Biol. 50: 571-99, 1999.

Venn S.E., Morgan J.W., Lord J.M.: Foliar freezing resistance of Australian alpine plants over the growing season. - Austral Ecol. 38: 152-161, 2013.

Wahid A., Gelani S., Ashraf M., Foolad M.R.: Heat tolerance in plants: An overview. - Environ. Exp. Bot. 64: $199-223,2007$.

Xin Z., Browse J.: Cold comfort farm: the acclimation of plants to freezing temperatures. - Plant Cell Environ. 20: 893-902, 2000. 


\section{Figures legends}

Figure 1. Daily minimum absolute, maximum absolute and mean air temperatures of the studied area. Essays: E1 (17 $7^{\text {th }}$ December), E2 (14 February), E3 (25 $5^{\text {th }}$ February) and E4 (24 ${ }^{\text {th }}$ July).

Figure 2. $\mathrm{F}_{\mathrm{v}} / \mathrm{F}_{\mathrm{m}}$ and $\mathrm{R}_{\mathrm{fd}}$ values correlation in $P$. lasiospermus. High temperatures $(A)$ include data from $20^{\circ} \mathrm{C}$ to $50^{\circ} \mathrm{C}$ treatments. Low temperatures $(B)$ include data from $0^{\circ} \mathrm{C}$ to $-20^{\circ} \mathrm{C}$ treatments (E4 data excluded). Open circles: low temperatures data of $\mathrm{E} 4$ ( $24^{\text {th }}$ July). $p$-value $<0.05$ in both regression models.

Figure 3. Percentage of damage at high and low temperature treatments in $P$. lasiospermus using $F_{v} / F_{m}$ and $R_{f d}$ percentage of control reduction as indicators of damage in four different moments during the studied period. Data are the mean values \pm standard error ( $n=5-9$ ).

Figure 4. Changes in $\mathrm{LT}_{50}$ values obtained from $\mathrm{F}_{\mathrm{v}} / \mathrm{F}_{\mathrm{m}}$ (close circles) and $\mathrm{R}_{\mathrm{fd}}$ (open circles) through the year at high $(A)$ and low $(B)$ temperatures. Estimated mean values \pm confidence interval obtained by the regression model. $p$-value $<0.05$. 